\title{
Pharmacokinetics, immunogenicity and safety of bivatuzumab mertansine, a novel CD44v6-targeting immunoconjugate, in patients with squamous cell carcinoma of the head and neck
}

\author{
ALEXANDER SAUTER $^{1}$, CHARLOTTE KLOFT ${ }^{2}$, SILKE GRONAU $^{3}$, FELIX BOGESCHDORFER ${ }^{3}$, \\ THOMAS ERHARDT ${ }^{4}$, WOLFRAM GOLZE ${ }^{1}$, CARSTEN SCHROEN $^{3}$, ALEXANDER STAAB $^{5}$, \\ HERBERT RIECHELMANN $^{3}$ and KARL HOERMANN ${ }^{1}$
}

\begin{abstract}
${ }^{1}$ Department of Otorhinolaryngology, Head and Neck Surgery, University Hospital Mannheim; ${ }^{2}$ Department of Clinical Pharmacy, Martin-Luther-Universitaet Halle-Wittenberg; ${ }^{3}$ Department of Otorhinolaryngology, Head and Neck Surgery, University of Ulm; ${ }^{4}$ Department of Otorhinolaryngology, Head and Neck Surgery, University of Homburg; ${ }^{5}$ Boehringer Ingelheim Pharma GmbH \& Co. KG, Biberach, Germany
\end{abstract}

Received November 1, 2006; Accepted December 29, 2006

\begin{abstract}
The prodrug bivatuzumab mertansine (BIWI 1) is a novel CD44v6-targeting humanized monoclonal antibody coupled to the toxin mertansine. In a phase I dose escalation trial 31 patients with squamous cell carcinomas of the head and neck were treated with doses of $25-325 \mathrm{mg} / \mathrm{m}^{2}$ as a $30-\mathrm{min}$ infusion. Thirteen patients received a second infusion after 3 weeks. Serial serum samples were collected to determine the pharmacokinetic parameters of the prodrug BIWI 1 and of deconjugated BIWI 1 as well as the occurrence of anti-BIWI 1 antibodies. The maximum tolerated dose was reached at $300 \mathrm{mg} / \mathrm{m}^{2}$ attributable to skin toxicity. No immune response was observed in any patient. For BIWI 1 and deconjugated BIWI 1, clearance values were low and distribution was limited resulting in half-lives of $\sim 3-3.5$ days and $\sim 6-7$ days, respectively, for single and repeated dosing after three weeks. Overall, interindividual variability of the pharmacokinetic parameters was low. In general, the pharmacokinetics of both compounds after single and repeated dosing was comparable across the entire dose range and no significant accumulation took place. Over the dose range investigated, a dose proportional increase in the exposure of BIWI 1 and deconjugated BIWI 1 was observed. Dose individualization according to body size (weight or body surface area) was found to be appropriate and is recommended for the novel immunoconjugate.
\end{abstract}

Correspondence to: Professor Charlotte Kloft, Department of Clinical Pharmacy, Faculty of Pharmacy, Martin-Luther-Universitaet Halle-Wittenberg, Wolfgang-Langenbeck-Str. 4, D-06120 Halle, Germany

E-mail: charlotte.kloft@pharmazie.uni-halle.de

Key words: bivatuzumab mertansine, BIWI 1, CD44v6, squamous cell carcinoma, head and neck cancer, pharmacokinetics, maximum tolerated dose

\section{Introduction}

Squamous cell carcinomas of the head and neck (HNSCC) account for $\sim 5 \%$ of all malignant neoplasms in Europe and the United States. The worldwide incidence is estimated to be $\sim 500,000 /$ year (1). Current standard therapeutic options for HNSCC patients comprise surgery or radiotherapy (2). While the prognosis for $1 / 3$ early-stage disease patients (stage I/II) is good, the remaining $2 / 3$ patients with advanced disease (stage III/IV) show relapse and distant metastases in $40 \%$ and $25-57 \%$, respectively, suggesting residual tumor mass (3-5). Hence, adjuvant chemotherapy was introduced as a beneficial addition for patients with advanced HNSCC (2) but the increase in survival was limited (6). New adjuvant therapeutic options are, thus, highly needed (7).

Immunotherapies with monoclonal antibodies (mAbs) targeting tumor-associated antigens expressed on the surface of squamous carcinoma cells such as E48 (8) and CD44 splice variants containing the v6 domain (CD44v6) represent an attractive novel molecular approach to selectively deliver toxic agents to tumor cells $(8,9)$. Initial efforts concentrated on the development of radioimmunoconjugates of mAbs directed against CD44v6 for radioimmunotherapy $(10,11)$. Clinical trials with the ${ }^{186} \mathrm{Re}$-labeled bivatuzumab demonstrated promising anti-tumor effects with good tolerability (12). Bivatuzumab (BIWA 4) is a humanized IgG1 mAb recognizing the domain v6 of CD44 which is uniformly expressed on the vast majority of squamous cell carcinomas (13).

Recently, non-radioactive immunoconjugates have been developed where the cytotoxic agent mertansine was covalently coupled to mAbs, e.g. bivatuzumab or cantuzumab, in a molecular ratio of about 3:1 (14; Heider et al, 17th AACRNCI-EORTC International Conference on molecular targets and cancer therapeutics, abs. A52, 2005). Mertansine is a derivative of the antimicrotubule agent maytansine, displaying a 100 -to- 1000-fold higher cytotoxic activity than other clinically used anticancer drugs, e.g. taxanes or anthracyclines (15). After binding to the target antigen, e.g. CD44v6, the 
antibody-mertansine complex is internalized and the mertansine molecules are released by cleavage of the mAb-mertansine disulphide bonds. Mertansine inhibits tubulin polymerization, thereby disrupting microtubule assembly leading to mitotic arrest and finally tumor cell death (16).

With the prodrug bivatuzumab mertansine (BIWI 1) a dose escalation clinical trial was performed in patients with advanced HNSCC. The aim of the present study was to characterize the pharmacokinetics and immunogenicity of the novel immunoconjugate. As dose was adjusted to body surface area this approach should also be evaluated. In addition, we here report preliminary safety results with data for the maximum tolerated dose of bivatuzumab mertansine.

\section{Materials and methods}

Study design and treatment protocol. Adult patients suffering from recurrent, inoperable or metastatic HNSCC were eligible for this phase I trial with accelerated dose titration. The study was performed in accordance with the Declaration of Helsinki, Version of 1996 (17) and approved by the Independent Ethics Committees of the participating sites. All patients gave written informed consent prior to inclusion.

Treatment started with a single intravenous dose of bivatuzumab mertansine (BIWI 1) followed by a three-week observation period (= 1 course). Patients who experienced clinical benefit and had recovered from any drug-related adverse event were eligible for repeated courses. Bivatuzumab mertansine was administered as an intravenous infusion over $30 \mathrm{~min}$. Each infusion of bivatuzumab mertansine was followed by a $100-\mathrm{ml}$ wash of the tubing system with $0.9 \%$ $\mathrm{NaCl}$ and a $10-\mathrm{ml} \mathrm{NaCl}$ flush of the venous access ( $\sim 15 \mathrm{~min})$. The starting dose of the trial was planned to be $25 \mathrm{mg} / \mathrm{m}^{2}$ bivatuzumab mertansine with $25 \mathrm{mg} / \mathrm{m}^{2}$ escalating increments. Before entering a new patient at the next higher dose level it had to be ensured that the patient at the ongoing level did not experience any drug-related adverse events of grade $>2$ common toxicity criteria (CTC) (18). As soon as one patient experienced drug-related CTC grade $>2$ at a certain dose level, a further two patients had to be treated at that and each higher dose level. When at the ongoing dose level one patient experienced previously defined dose-limiting toxicity (DLT) the number of patients treated at that dose level had to be increased to a total of 6 patients. DLT was defined as drugrelated CTC grade $\geq 3$ non-hematological toxicity excluding nausea and vomiting or drug-related CTC grade 4 neutropenia for at least 4 days and/or complicated by infection or drugrelated thrombocytopenia of $<25,000 / \mathrm{ml}$. The maximum tolerated dose (MTD) was the highest dose at which none of the patients or no more than one patient out of six experienced DLT.

Safety assessment. For safety evaluation adverse events with their intensity assessed according to CTC version 2, laboratory evaluation and vital signs were recorded.

Serum sampling. Serial $6 \mathrm{ml}$ blood samples were to be taken pre- and post-infusion at 5 min after the $\mathrm{NaCl}$ flush (i.e. after the end of the bivatuzumab mertansine infusion and the $100 \mathrm{ml}$ $+10 \mathrm{ml} \mathrm{NaCl}$ wash steps of the tubing system and venous access, respectively), and at 2, 4, 8 and $24 \mathrm{~h}$ as well as at any time during days $4,7,10,14$ and 21 after the start of infusion. Blood on day 1 had to be drawn from the arm contralateral to the one where the infusion was given. Blood was collected in a non-anticoagulant tube, allowed to clot and centrifuged at $4-8^{\circ} \mathrm{C}$ to prepare $\sim 3 \mathrm{ml}$ serum for the determination of: i) the concentrations of the prodrug BIWI 1 (bivatuzumab mertansine) and of anti-CD44v6 antibody (representing the sum of intact bivatuzumab mertansine plus any mertansineconjugated or -deconjugated $\mathrm{IgG} 1$ antibody recognizing CD44v6); and ii) the occurrence of human anti-human antibodies (HAHA), i.e. anti-BIWI 1 antibodies, but only in pre-infusion and day 21 samples.

For the repeated course after 3 weeks the same sampling schedule as for the first course was applied except for 1 patient where a reduced sampling schedule was used (predose, after infusion and washing/flushing, $3 \mathrm{~h}$ after start of infusion and at any time on day 21).

Drug concentration assay-BIWI 1. Serum concentrations of BIWI 1 were determined by an enzyme linked immunosorbent assay (ELISA) where a sandwich complex of: i) antigen (glutathion S-transferase-CD44v6 immobilized on microtiter plates); ii) the analyte BIWI 1; and iii) detector antibody (selective anti-mertansine, biotinylated monoclonal mouse antibody) was formed. The complex was photometrically detected after incubation with streptavidinperoxidase and a chromogenic substrate. The sandwich ELISA had a lower limit of quantification (LLOQ) of $2 \mathrm{ng} / \mathrm{ml}$ $(\sim 13 \mathrm{pM})$, respectively.

Drug concentration assay-anti-CD44v6 antibodies. The analyte representing the sum of intact BIWI 1 plus any IgG antibody recognizing CD44v6, was quantified using also a sandwich type ELISA with the same antigen as described above. However, the detector antibody was an enzyme labeled, polyclonal rabbit anti-human IgG antibody. After incubation with a chromogenic substrate the sandwich complexes formed were detected photometrically. The lower limit of quantification of this ELISA was $100 \mathrm{ng}$ anti-CD44v6 antibody equivalents/ml serum corresponding to a LLOQ of $\sim 0.67 \mathrm{nM}$.

Deconjugated BIWI 1 concentrations (bivatuzumab without mertansine, however, the linker or parts of the linker might still be present) were calculated by subtracting the measured BIWI 1 concentrations from the respective measured antiCD44v6 antibody concentrations.

Immunogenicity assay-anti-BIWI 1 antibodies. The presence of anti-BIWI 1 antibodies as human anti-human antibodies (HAHA) was evaluated by a selective ELISA of the double antigen or bridging type. Due to a missing positive human anti-BIWI 1 serum which could be used as standard, the validation of the present assay was carried out using polyclonal rabbit anti-BIWI $1 \mathrm{IgG}$ antibodies that were purified from serum using protein $\mathrm{A}$. As it is not possible to absolutely quantify the antibody concentrations in terms of antibody mass/volume relative measurements of anti-BIWI 1 concentration in ng reference antibody equivalents $/ \mathrm{ml}$ were obtained. Serum samples $(100 \mu 1)$ were required and diluted with serum (1:5) resulting in a quasi 'lower limit of quantification' 
Table I. Patient demographics $(n=31)$ at the beginning of the study.

\begin{tabular}{lcccc}
\hline & $\begin{array}{c}\text { Age } \\
(\text { years })\end{array}$ & $\begin{array}{c}\text { Weight } \\
(\mathrm{kg})\end{array}$ & $\begin{array}{c}\text { Height } \\
(\mathrm{cm})\end{array}$ & $\begin{array}{c}\text { BSA } \\
\left(\mathrm{m}^{2}\right)\end{array}$ \\
\hline Mean & 60 & 64 & 173 & 1.76 \\
Median & 61 & 62 & 172 & 1.75 \\
Minimum & 46 & 43 & 159 & 1.42 \\
Maximum & 75 & 98 & 192 & 2.17 \\
CV $(\%)$ & 12.6 & 20.2 & 4.1 & 10.4 \\
\hline
\end{tabular}

of $10 \mathrm{ng}$ equivalents/ml serum. All samples with a response above the cut-off value of $10 \mathrm{ng} / \mathrm{ml}$ were considered to indicate a positive anti-BIWI 1 immune response. These samples were further characterized by a blocking experiment with BIWI 1 and other test reagents in order to verify a true positive anti-BIWI 1 immune response.

In all three bioanalytical assays accuracy and precision parameters met international criteria (19).

Pharmacokinetic analysis. The pharmacokinetic (PK) properties of BIWI 1 and deconjugated BIWI 1 were determined by non-compartmental analysis (20) of the serum-concentration time data using the software WinNonlin ${ }^{\mathrm{TM}}$, version 4.1 (Pharsight Corp., Mountain View, CA). For analysis the actual administered doses and actual blood sampling times were used. As infusion duration the sum of infusion and washing/ flushing time was used. The relevant pharmacokinetic parameters were determined for BIWI 1 and deconjugated BIWI 1 per individual and per course as follows: $\mathrm{C}_{\max }$, the observed maximum concentrations with the corresponding sampling timepoints, $\mathrm{t}_{\max }$, were directly taken from the entire individual concentration-time profiles. The apparent terminal rate constant, $\lambda_{\mathrm{z}}$, associated with the apparent terminal (loglinear) portion of the profile as first-order rate constant was determined from the slope of the regression of $1 n$ (concentration) versus time. The apparent terminal half-life, $\mathrm{t}_{1 / 2}$, was then calculated by $\mathrm{t}_{1 / 2}=\ln (2) / \lambda \mathrm{z}$. Area under the serum-concentration time curve (AUC) was calculated for two different time periods using the log-linear trapezoidal rule (20). $\mathrm{AUC}_{0-168}$ and $\mathrm{AUC}_{0-\infty}$ represented the areas from 0 to $168 \mathrm{~h}$ and to infinity, respectively. The extrapolated area from the last time point with a serum concentration above the lower quantification limit $\left(\mathrm{t}_{\mathrm{z}}\right)$ to infinity was calculated by $\mathrm{C}_{\mathrm{tz}}^{\prime} / \lambda_{\mathrm{z}}$, where $\mathrm{C}_{\mathrm{tz}}^{\prime}$ was the predicted concentration at $\mathrm{t}_{\mathrm{z}}$. In addition, for BIWI 1 clearance (CL) was determined by dividing the dose by $\mathrm{AUC}_{0-\infty}$, and the mean residence time (MRT) by $\left(\mathrm{AUMC}_{0-\infty} / \mathrm{AUC}_{0-\infty}\right)-0.5$ infusion duration, where $\mathrm{AUMC}_{0-\infty}$ is the area under the first moment curve. Finally the volume of distribution was calculated by multiplying $\mathrm{CL}$ with MRT.

Statistical analysis. Due to the exploratory nature of this phase I trial results will be presented descriptively with location and dispersion parameters. Where applicable, results
A

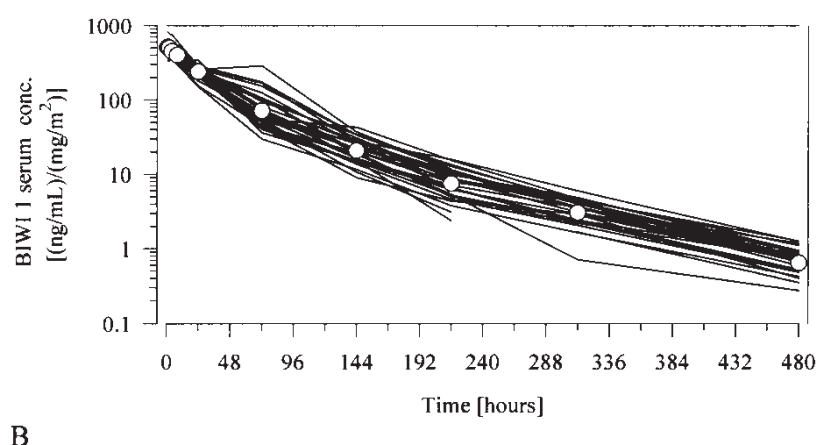

B

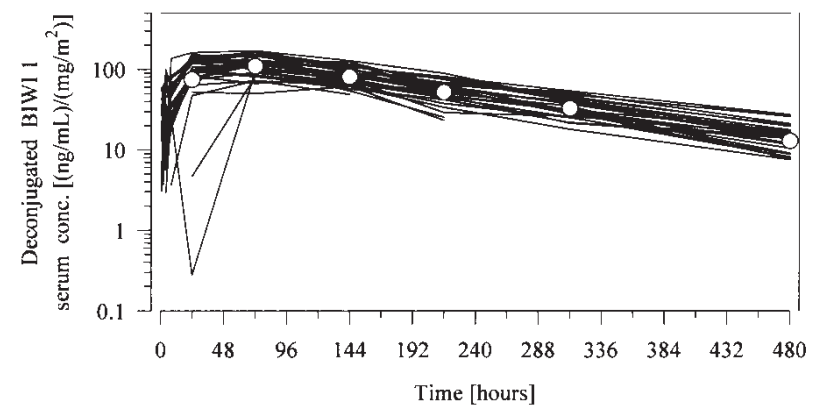

Figure 1. Semi-logarithmic dose-normalised individual (-) and geometric mean (o) serum concentration-time profiles of BIWI $1(\mathrm{~A}, \mathrm{n}=31)$ and deconjugated BIWI $1(\mathrm{~B}, \mathrm{n}=31)$ after the first 0.5 -h infusion of bivatuzumab mertansine.

are presented as geometric mean and coefficient of variation, $\mathrm{gCV}$ (given in \%), or median and range.

\section{Results}

Patient population. Thirty-one patients ( 6 female, 25 males; aged 46-75 years) with advanced HNSCC entered the trial. All of them were treated with bivatuzumab mertansine in the open single dose escalation study between September 2002 and November 2004. The actual dose range investigated was $25-325 \mathrm{mg} / \mathrm{m}^{2}$ where dose-limiting toxicity was observed, corresponding to $54-637 \mathrm{mg}$ absolute doses with 1 patient per dose tier up to $175 \mathrm{mg} / \mathrm{m}^{2}$ and 3 patients thereafter except in the $300 \mathrm{mg} / \mathrm{m}^{2}$ dose group with 6 additional patients. Thirteen patients underwent repeated courses but only 12 of them had extensive sampling in the first repeated course. The patient demographic characteristics at the start of the PK study are summarized in Table I.

Safety and maximum tolerated dose. The primary target tissue of bivatuzumab mertansine for toxicity was the skin. Serious and non-serious skin-related adverse events were reversible with and without local and systemic therapy. Skin reactions were the dose limiting toxicity (DLT) determining the maximum tolerated dose (MTD) of $300 \mathrm{mg} / \mathrm{m}^{2}$ bivatuzumab mertansine.

BIW1 1 and deconjugated BIWI 1 drug assays and documentation. In one patient concentrations of BIWI 1 and deconjugated BIWI 1 were detected in the pre-dose sample of the first course. These were excluded from the dataset for 
A

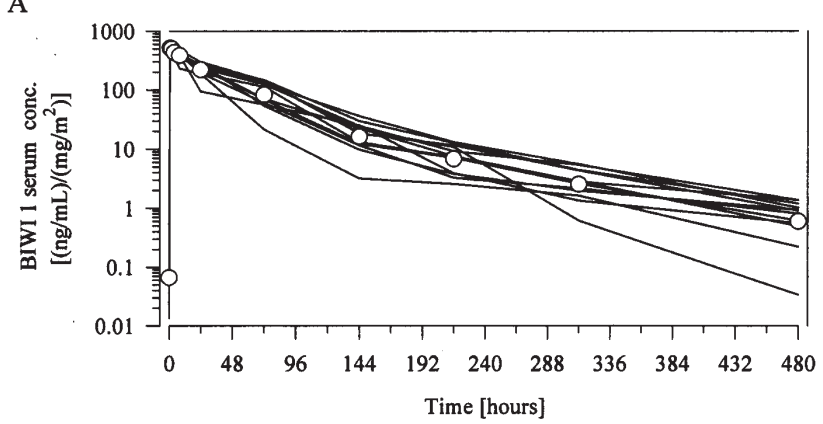

B

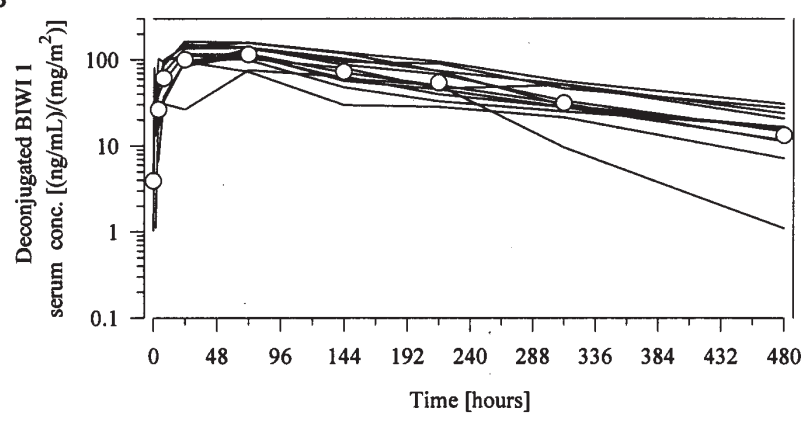

Figure 2. Semi-logarithmic dose-normalized individual (-) and geometric mean $(0)$ serum concentration-time profiles of BIWI $1(A, n=12)$ and deconjugated BIWI $1(\mathrm{~B}, \mathrm{n}=12)$ after the repeated 0.5 -h infusion of bivatuzumab mertansine.

analyses. Furthermore, the duration of the washing/flushing procedure of the administration system for that patient was not recorded. Thus, only the infusion time was used as infusion duration.

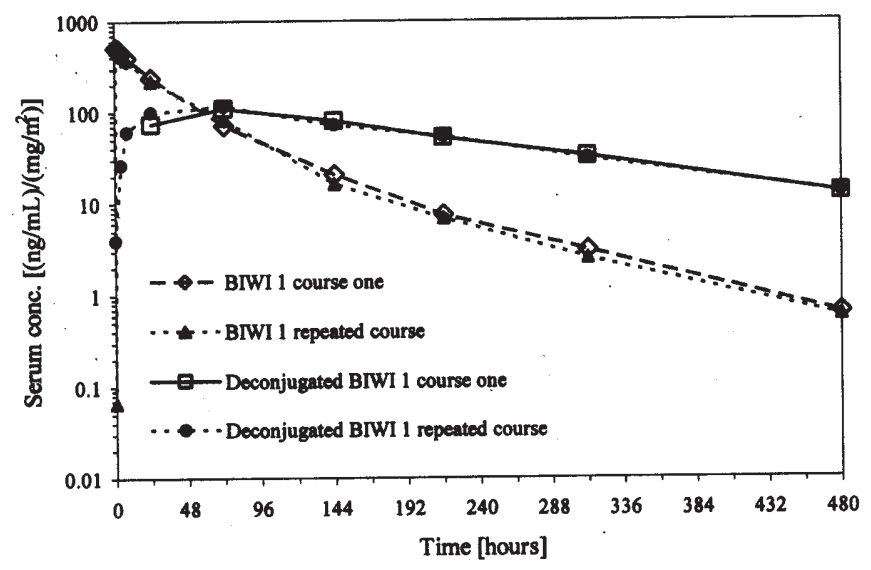

Figure 3. Semi-logarithmic dose-normalized geometric mean serum concentration-time profiles of BIWI 1 and deconjugated BIWI 1 after the first $(\mathrm{n}=31)$ and the repeated $(\mathrm{n}=12) 0.5$-h infusion of bivatuzumab mertansine.

Concentration-time profiles of BIWI 1 and deconjugated $B I W I$ 1. Individual and geometric mean serum concentrationtime profiles of BIWI 1 and deconjugated BIWI 1 after the first infusion of BIWI 1 are displayed in Fig. 1. Due to the wide dose range administered all drug concentrations were dose-normalized to a dose of $1 \mathrm{mg} / \mathrm{m}^{2}$.

Whereas over the 3 -week observation period the mean BIWI 1 concentration only declined with 2 distinct phases, the mean concentration of deconjugated BIWI 1 first increased for 2-3 days after mAb infusion and subsequently decreased in a monophasic manner over time. On average, BIWI 1 concentrations exceeded the deconjugated BIWI 1 concentration

Table II. Pharmacokinetic parameters of BIWI 1 after a 0.5 -h infusion of bivatuzumab mertansine, determined by noncompartmental analysis.

$\begin{array}{lcccccc}\mathrm{C}_{\text {max norm }} & \mathrm{AUC}_{0-168, \text { norm }} & \mathrm{AUC}_{0-\infty, \text { norm }} & \mathrm{CL} & \mathrm{V} & \mathrm{t}_{\max } & \mathrm{t}_{1 / 2} \\ {[(\mu \mathrm{g} / \mathrm{ml}) /} & {[(\mu \mathrm{g} \cdot \mathrm{h} / \mathrm{ml}) /} & {[(\mu \mathrm{g} \cdot \mathrm{h} / \mathrm{ml}) /} & (\mathrm{ml} / \mathrm{min}) & (\mathrm{l}) & (\mathrm{h}) & (\mathrm{h}) \\ \left.\left(\mathrm{mg} / \mathrm{m}^{2}\right)\right] & \left.\left(\mathrm{mg} / \mathrm{m}^{2}\right)\right] & \left.\left(\mathrm{mg} / \mathrm{m}^{2}\right)\right] & & & & \end{array}$

\section{Course one}

\section{$\mathrm{N}$}

gMean $^{\mathrm{a}}$

$\operatorname{gCV}(\%)^{\mathrm{b}}$

0.530

31

18.4

15.3

16.2

30.1
16.2

31

31

31

31

Median

16.2

1.45

5.25

19.0

21.3

Minimum

Maximum

Maximum

Repeated course

\begin{tabular}{lcccccc}
$\mathrm{N}$ & 12 & 12 & 12 & 12 & 12 & 12 \\
gMean $^{\mathrm{a}}$ & 0.518 & 18.0 & 19.6 & 1.47 & 5.44 & 12 \\
$\mathrm{gCV}(\%)^{\mathrm{b}}$ & 8.86 & 11.3 & 12.4 & 16.7 & 14.0 & 0.775 \\
Median & & & & & 81.1 \\
Minimum & & & & & 0.583 & 75.8 \\
Maximum & & & & 2.08 & 148 \\
\hline
\end{tabular}

${ }^{\mathrm{a}}$ Geometric mean. ${ }^{\mathrm{b}}$ Geometric coefficient of variation. 
Table III. Pharmacokinetic parameters of deconjugated BIWI 1 after a 0.5 -h infusion of bivatuzumab mertansine, determined by non-compartmental analysis.

\begin{tabular}{lcccc}
$\mathrm{C}_{\max , \text { norm }}$ & $\mathrm{AUC}_{0-168, \text { norm }}$ & $\mathrm{AUC}_{0-\infty, \text { norm }}$ & $\mathrm{t}_{\max }$ & $\mathrm{t}_{1 / 2}$ \\
{$[(\mu \mathrm{g} / \mathrm{ml}) /$} & {$[(\mu \mathrm{g} \cdot \mathrm{h} / \mathrm{ml}) /$} & {$[(\mu \mathrm{g} \cdot \mathrm{h} / \mathrm{ml}) /$} & $(\mathrm{h})$ & $(\mathrm{h})$ \\
$\left.\left(\mathrm{mg} / \mathrm{m}^{2}\right)\right]$ & $\left.\left(\mathrm{mg} / \mathrm{m}^{2}\right)\right]$ & $\left.\left(\mathrm{mg} / \mathrm{m}^{2}\right)\right]$ & & \\
\hline
\end{tabular}

\begin{tabular}{|c|c|c|c|c|c|}
\hline \multicolumn{6}{|l|}{ Course one } \\
\hline $\mathrm{N}$ & 31 & 31 & 31 & 31 & 31 \\
\hline gMean ${ }^{\mathrm{a}}$ & 0.114 & 14.8 & 30.0 & & \\
\hline $\operatorname{gCV}(\%)^{\mathrm{b}}$ & 26.7 & 28.0 & 23.3 & & \\
\hline Median & & & & 68.9 & 141 \\
\hline Minimum & & & & 22.0 & 86.0 \\
\hline Maximum & & & & 173 & 275 \\
\hline \multicolumn{6}{|c|}{ Repeated course } \\
\hline $\mathrm{N}$ & 12 & 12 & 12 & 12 & 12 \\
\hline gMean $^{\mathrm{a}}$ & 0.120 & 15.8 & 32.9 & & \\
\hline $\mathrm{gCV}(\%)^{\mathrm{b}}$ & 22.8 & 25.2 & 25.6 & & \\
\hline Median & & & & 46.6 & 173 \\
\hline Minimum & & & & 21.5 & 121 \\
\hline Maximum & & & & 72.0 & 225 \\
\hline
\end{tabular}

${ }^{\mathrm{a}}$ Geometric mean. ${ }^{\mathrm{b}} \mathrm{Geometric} \mathrm{coefficient} \mathrm{of} \mathrm{variation.}$

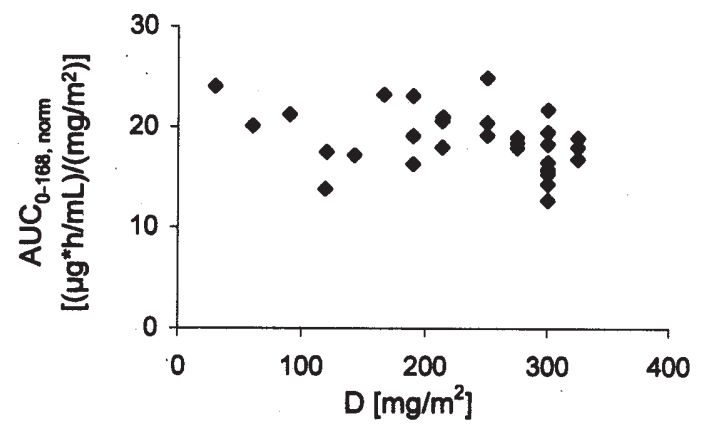

Figure 4. Individual dose-normalized AUC values $\left(\mathrm{AUC}_{0-168, \text { norm }}\right)$ of BIWI 1 after the first infusion of bivatuzumab mertansine vs. dose $(n=31)$.

only during the first day and after being approximately equal on day 2 , the concentrations of deconjugated BIWI 1 were above those of BIWI 1.

Compared to the first infusion the dose-normalized concentration-time profiles after the repeated course were similar in size, shape and spread with the exception of measurable pre-infusion concentrations of BIWI 1 and deconjugated BIWI 1 (Figs. 2 and 3).

Pharmacokinetic data analysis and parameters. All individual concentration-time profiles were evaluable by noncompartmental pharmacokinetic (PK) analysis. The PK parameters of BIWI 1 and deconjugated BIWI 1 are summarized with the respective descriptive statistics in Tables II and III. Concentration-dependent-parameters such as $\mathrm{C}_{\max }$ and AUC values were normalized to a dose of $1 \mathrm{mg} / \mathrm{m}^{2}$. Whereas maximum concentrations of BIWI 1 [geometric mean: $\left.0.530(\mu \mathrm{g} / \mathrm{ml}) /\left(\mathrm{mg} / \mathrm{m}^{2}\right)\right]$ were reached after $0.767 \mathrm{~h}$, i.e. approximately at the end of the infusion and the washing/ flushing procedures of the administration system, the maximum concentrations of deconjugated BIWI 1 [geometric mean: $\left.0.114(\mu \mathrm{g} / \mathrm{ml}) /\left(\mathrm{mg} / \mathrm{m}^{2}\right)\right]$ occurred at much later time points of 68.9 h. Both time points varied among patients ranging from $\sim 1 / 2$ h to $\sim 4 \mathrm{~h}$ and $\sim 1$ to $\sim 7$ days for BIWI 1 and deconjugated BIWI 1, respectively.

After the repeated BIWI 1 infusions, $\mathrm{C}_{\max }$ of BIWI 1 and deconjugated BIWI 1 [geometric means: 0.518 and 0.120 $(\mu \mathrm{g} / \mathrm{ml}) /\left(\mathrm{mg} / \mathrm{m}^{2}\right)$, respectively] were very similar to those after the first course. While the median $t_{\max }$ value for BIWI 1 $(0.775 \mathrm{~h})$ was also comparable to the first course, the value was lower for deconjugated BIWI $1(46.6 \mathrm{~h})$ but still considerably later than for BIWI 1. In total, geometric coefficients of variation of $\mathrm{C}_{\max }$ were low $(<27 \%)$ after the first or repeated course. The highest individual concentration of BIWI 1 was $176 \mu \mathrm{g} / \mathrm{ml}$ and of deconjugated BIWI 1 was $50.8 \mu \mathrm{g} / \mathrm{ml}$.

Dose-normalized areas under the serum-concentration time curve for the periods from 0 to $168 \mathrm{~h}\left(\mathrm{AUC}_{0-168}\right)$ or to infinity $\left(\mathrm{AUC}_{0-\infty}\right)$ of BIWI 1 and deconjugated BIWI 1 did not differ in size or variability between the first and repeated course. $\mathrm{AUC}_{0-168}$ and $\mathrm{AUC}_{0-\infty}$ values of BIWI 1 were very similar indicating that only a small part was based on extrapolation whereas for deconjugated BIWI 1 approximately $50 \%$ of the $\mathrm{AUC}_{0-\infty}$ was extrapolated.

Fig. 4 depicts the dose-normalized $\mathrm{AUC}_{0-168}$ values of BIWI 1 versus dose. The data suggest no trend for the dosenormalized $\mathrm{AUC}_{0-168}$ values and, hence, a dose proportional increase in non-normalized $\mathrm{AUC}_{0-168}$ in the dose range from 25 to $325 \mathrm{mg} / \mathrm{m}^{2}$ can be assumed. 
A

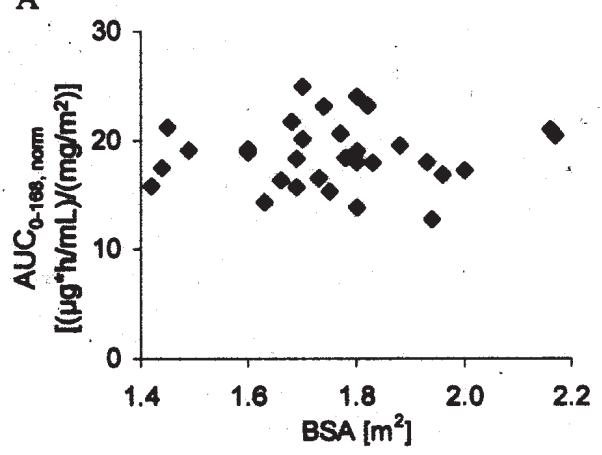

B

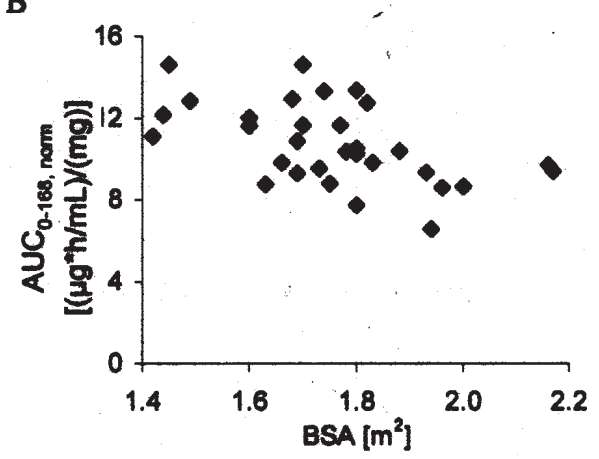

Figure 5. Individual dose-normalized [to $1 \mathrm{mg} / \mathrm{m}^{2}$, (A) or to $1 \mathrm{mg}$ (B)] AUC values (AUC $\mathrm{A}_{0-168, \text { norm }}$ ) of BIWI 1 after the first administration of bivatuzumab mertansine vs. BSA $(n=31)$.

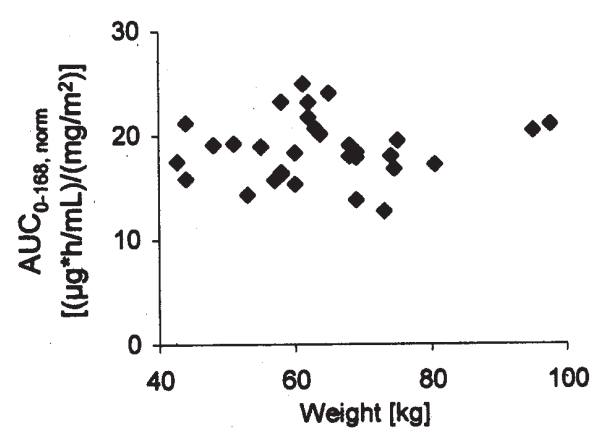

Figure 6. Individual dose-normalized (to $\left.1 \mathrm{mg} / \mathrm{m}^{2}\right)$ AUC values $\left(\mathrm{AUC}_{0-168, \text { norm }}\right)$ of BIWI 1 after the first administration of bivatuzumab mertansine vs. weight $(n=31)$.

Mean clearance and volume of distribution values of BIWI 1 after the first administration were low with $1.45 \mathrm{ml} /$ min and 5.251 resulting in a median half-life of $75.8 \mathrm{~h}$. After repeated courses the values were comparable being $1.47 \mathrm{ml} / \mathrm{min}$, 5.441 and $81.1 \mathrm{~h}$, respectively. Half-life of deconjugated BIWI 1 was significantly longer (first course: $141 \mathrm{~h}$; repeated course: $173 \mathrm{~h}$ ) than of BIWI 1.

In total, interindividual variability in the pharmacokinetic parameters of BIWI 1 and deconjugated BIWI 1 was relatively low. In order to evaluate whether dose adjustment to body surface area (BSA) was appropriate exposure expressed as $\mathrm{AUC}_{0-168}$, normalized to a dose of $1 \mathrm{mg} / \mathrm{m}^{2}$ or of $1 \mathrm{mg}$ was plotted against BSA (Fig. 5). The lower variability and more random spread in the left panel where dose normalization by $\mathrm{mg} / \mathrm{m}^{2}$ is shown indicate that dose individualization by body size resulted in more similar exposure of bivatuzumab mertansine in all patients than giving the same absolute dose to all patients. Fig. 6 illustrates that dose individualization by weight would also be appropriate.

Anti-BIWI 1 antibodies - immunogenicity response. In none of the 31 patients were anti-BIWI 1 antibodies such as HAHA detectable, i.e. no positive anti-BIWI 1 immune response was observed.

\section{Discussion}

Immunotoxic conjugates are becoming an attractive component of anticancer treatment. Highly toxic agents which display an unfavorable therapeutic index if administered as single agents are coupled to monoclonal antibodies (21). By combining the exquisite targeting specificity of mAbs with the enhanced tumor-killing power of cytotoxic molecules, immunoconjugates permit better discrimination between antigen-positive malignant cells and antigen-negative healthy tissue, resulting in less systemic toxicity than most conventional chemotherapeutic drugs. One monoclonal antibody conjugate, gemtuzumab ozogamicin (Mylotarg ${ }^{\mathrm{TM}}$ ), has already been approved where the potent toxin calicheamicin has been conjugated to an anti-CD33 antibody (22). In the present study, a pharmacokinetic, immunogenicity and preliminary safety analysis was performed with the immunoconjugate bivatuzumab mertansine, where the cytotoxic agent mertansine is coupled to the monoclonal antibody bivatuzumab. The humanized IgG1 monoclonal antibody is directed against CD44v6, a promising target on the surface of malignant squamous cells. This phase I single dose escalation trial with bivatuzumab mertansine in patients with advanced squamous cell carcinomas of the head and neck (HNSCC) was the first study that assessed the maximum tolerated dose (MTD) of this novel approach. Homogenous expression of CD44v6 has been observed in various malignancies, including squamous cell carcinoma of the lung, skin, esophagus and cervix, while heterogeneous expression was found in adenocarcinomas of the breast, colon, lung, pancreas and stomach (13). In normal tissues CD44v6 expression has been found in epithelial tissues such as skin, cervix, cornea, tonsil, breast, ureter, bladder and bronchial epithelium (23).

The main toxicity of bivatuzumab mertansine determining the MTD of $300 \mathrm{mg} / \mathrm{m}^{2}$ was related to skin which can be explained by binding of the antibody component bivatuzumab to keratinocytes. By immunohistochemistry skin keratinocytes stained positive for the CD44v6 antigen and accumulation of administered anti-CD44v6 mAbs in the basal skin layers had been observed in previous trials (11). In the present study, there were no indications for toxicity related to the free maytansine derivative mertansine, resulting from deconjugation. The main toxic effects of maytansine in the unconjugated form reported in phase I and II studies of the late 1980s were neural and gastrointestinal toxicities (24-27). Nevertheless, from the concentration-time profiles in Figs. 1 and 2 a slow but substantial deconjugation of bivatuzumab mertansine in the circulation may be derived. For another humanized 
mertansine-conjugated antibody with the same conjugation chemistry, cantuzumab mertansine, substantial deconjugation has also been reported $(15,28)$. Free mertansine plasma concentrations were measured in two patients by an ELISA of a protein-free extract of blood (15). Importantly, only up to $48 \mathrm{~h}$ after administration of the antibody conjugate, free mertansine was quantifiable in the plasma which always represented $<1 \%$ of the total circulating mertansine (antibody-conjugated mertansine plus free mertansine). These data suggest that free mertansine is rapidly eliminated from the circulation after formation.

The initially developed monoclonal antibody BIWA 1 against the target originated from a hybridoma clone of murine antibody-secreting B-cells. The radiolabeled $\mathrm{mAb}$ recognized the CD44v6 epitope and showed favorable biodistribution properties in a phase I study. However, in 11 of 12 patients anti-mouse antibodies were observed (11). To avoid the immune response especially after repeated dosing, a humanized IgG1 monoclonal antibody, bivatuzumab (BIWA 4), was developed. Clinical data from a phase I study of the ${ }^{186} \mathrm{Re}$-labeled $\mathrm{mAb}$ in patients with HNSCC, non-small cell lung cancer and adenocarcinoma of the breast showed good accumulation of the radionuclide indicating that the target was reached (12). Due to patient and environmental safety concerns, the humanized bivatuzumab mertansine now presents a non-radioactive labeled development of the "targeted therapy' approach. In the trial reported here, none of the 31 patients developed anti-BIWI 1 antibodies. This finding is in agreement with the low immunogenicity of the radiolabeled mAb observed by Colnot et al (29) and Koppe et al (30). As we did not observe any positive anti-BIWI 1 immune response either after single or multiple dosing the data suggest that bivatuzumab mertansine has no or only very little immunogenicity, at least after short-term administration.

Regarding the concentration-time courses and pharmacokinetic parameters of bivatuzumab mertansine several favorable properties were found. Serum concentration-time profiles of BIWI 1 were almost superimposable after the infusions of the first and repeated course suggesting minimal accumulation. BIWI 1 distributed into a restricted volume of approximately 51 which is consistent with the behavior of endogenous IgG immunoglobulins and exogenously administered specific therapeutic antibodies (31-33). Since the values for the distribution volume were slightly higher than the volume of plasma water additional but limited distribution outside serum into extravascular spaces was probable which was also observed for other mAbs $(32,34)$. In a previous investigation the cytotoxic agent mertansine was successfully delivered to its target antigen CD44v6 with its surface membrane localization on the squamous carcinoma cells as evidenced by radioactivity-labeled immunoconjugate (12).

Typical clearance values of humanized mAbs range between 3 and $100 \mathrm{ml} / \mathrm{h}(31,34)$ resulting in half-lives of approximately 8-15 days. The clearance of BIWI 1 was almost $90 \mathrm{ml} / \mathrm{h}$ and thus in the upper typical range. Interestingly, clearance after single and repeated dosing was very similar and constant over the entire dose range investigated. Therefore, the data suggest a linear pharmacokinetic behavior between $25-325 \mathrm{mg} / \mathrm{m}^{2}$. This finding is in accordance with other clinical pharmacokinetic studies on humanized monoclonal antibodies (35-39). However, for some mAbs also single nonlinear elimination or parallel non-linear and linear elimination pathways of the overall clearance were reported, i.e. clearance was not constant across a larger dose range but decreased with higher doses (40).

The estimated half-lives of BIWI 1 and deconjugated BIWI 1 were relatively long (3-7 days, respectively) compared to the vast majority of therapeutic agents but shorter than that of physiological and most humanized monoclonal $\mathrm{IgG} 1$ antibodies. The initial fast decline of BIWI 1 concentrations might be explainable by the quick cleavage of mertansine from the conjugated antibody. The second slower decline might be attributable to parallel processes such as cleavage of mertansine and the protective mechanism from elimination generally occurring for antibodies. The elimination of physiological IgG1 is believed to occur by slow and non-specific proteolytic degradation in hepatic endothelial and reticuloendothelial cells and proteasomes $(41,42)$. An additional contributing factor to the extremely long serum half-life of physiological IgG1 in humans of 18-21 days has been identified as the endocytosis and specific binding to intravesicular neonatal Fc receptors $(\mathrm{FcRn})$. This mechanism protects $\mathrm{IgG} 1$ molecules from intracellular degradation and returns them intact to the circulation (43). Thus, it is very likely that BIWI 1 elimination also occurred via the first-order process postulated for native $\operatorname{IgG} 1$. The reasons why the BIWI 1 showed a shorter half-life than physiological IgG1 antibodies might be the less efficient binding of the BIWI 1 molecules to FcRn and, hence, less efficient protection by FcRn.

The evaluation of the dose adjustment to body surface area (BSA) or body weight suggests that dose individualization according to body size seems appropriate. Due to the small sample size a conclusion whether dose should better be individualized on a $\mathrm{mg} / \mathrm{m}^{2}$ or $\mathrm{mg} / \mathrm{kg}$ basis cannot be drawn. Similar results (individualization to body size) were obtained for the chimeric antibody basiliximab (44) and the humanized antibodies daclizumab and sibrotuzumab $(40,45)$. In the case of sibrotuzumab, other measures of body size, including BSA, were inferior to body weight in explaining inter-patient variability.

In summary, the pharmacokinetic characteristics of bivatuzumab mertansine corresponded well to the known PK behavior of other humanized mAbs. The low variability in the pharmacokinetic properties after individualization of the dose to body size clearly supports such a recommendation.

\section{Acknowledgements}

The authors thank Ulrich Kunz, Boehringer Ingelheim Pharma GmbH \& Co. KG, for the bioanalytical determinations as well as Dorothea Frenzel, Martin-Luther-Universitaet, and Petra Prohaska, University Hospital Mannheim, for technical help. This study was financially supported by Boehringer Ingelheim Pharma GmbH \& Co KG, Biberach an der Riss, Germany.

\section{References}

1. Parkin DM, Bray F, Ferlay J and Pisani P: Estimating the world cancer burden: Globocan 2000. Int J Cancer 94: 153-156, 2001. 
2. Vokes EE, Weichselbaum RR, Lippman SM and Hong WK: Head and neck cancer. N Engl J Med 328: 184-194, 1993.

3. Dennington ML, Carter DR and Meyers AD: Distant metastases in head and neck epidermoid carcinoma. Laryngoscope 90: 196-201, 1980.

4. Nakanishi H, Oguri K, Takenaga K, Hosoda S and Okayama M: Differential fibrotic stromal responses of host tissue to low- and high- metastatic cloned Lewis lung carcinoma cells. Lab Invest 70: 324-332, 1994.

5. Zbaren P and Lehmann W: Frequency and sites of distant metastases in head and neck squamous cell carcinoma. An analysis of 101 cases at autopsy. Arch Otolaryngol Head Neck Surg 113: 762-764, 1987.

6. Forastiere A, Koch W, Trotti A and Sidransky D: Head and neck cancer. N Engl J Med 345: 1890-1900, 2001.

7. Al-Sarraf M: Treatment of locally advanced head and neck cancer: historical and critical review. Cancer Control 9: 387-399, 2002.

8. Brakenhoff RH, Gerretsen M, Knippels EM, van Dijk M, van Essen H, Weghuis DO, Sinke RJ, Snow GB and van Dongen GA: The human E48 antigen, highly homologous to the murine Ly-6 antigen ThB, is a GPI-anchored molecule apparently involved in keratinocyte cell-cell adhesion. J Cell Biol 129: 1677-1689, 1995.

9. Rubinfeld B, Upadhyay A, Clark SL, Fong SE, Smith V, Koeppen H, Ross S and Polakis P: Identification and immunotherapeutic targeting of antigens induced by chemotherapy. Nat Biotechnol 24: 205-209, 2006.

10. De Bree R, Roos JC, Quak JJ, den Hollander W, Snow GB and van Dongen GA: Radioimmunoscintigraphy and biodistribution of technetium-99m-labeled monoclonal antibody U36 in patients with head and neck cancer. Clin Cancer Res 1: 591-598, 1995.

11. Stroomer JW, Roos JC, Sproll M, Quak JJ, Heider KH, Wilhelm BJ, Castelijns JA, Meyer R, Kwakkelstein MO, Snow GB, Adolf GR and van Dongen GA: Safety and biodistribution of $99 \mathrm{mTechnetium-labeled} \mathrm{anti-CD44v6} \mathrm{mono-}$ clonal antibody BIWA 1 in head and neck cancer patients. Clin Cancer Res 6: 3046-3055, 2000.

12. Borjesson PK, Postema EJ, Roos JC, Colnot DR, Marres HA, van Schie MH, Stehle G, De Bree R, Snow GB, Oyen WJ and van Dongen GA: Phase I therapy study with (186)Re-labeled humanized monoclonal antibody BIWA 4 (bivatuzumab) in patients with head and neck squamous cell carcinoma. Clin Cancer Res 9: 3961S-3972S, 2003.

13. Heider KH, Sproll M, Susani S, Patzelt E, Beaumier P, Ostermann E, Ahorn $\mathrm{H}$ and Adolf GR: Characterization of a high-affinity monoclonal antibody specific for CD44v6 as candidate for immunotherapy of squamous cell carcinomas. Cancer Immunol Immunother 43: 245-253, 1996.

14. Tolcher AW, Ochoa L, Hammond LA, Patnaik A, Edwards T, Takimoto C, Smith L, De Bono J, Schwartz G, Mays T, Jonak ZL, Johnson R, De Witte M, Martino H, Audette C, Maes K, Chari RV, Lambert JM and Rowinsky EK: Cantuzumab mertansine, a maytansinoid immunoconjugate directed to the CanAg antigen: a phase I, pharmacokinetic, and biologic correlative study. J Clin Oncol 21: 211-222, 2003.

15. Liu C and Chari RV: The development of antibody delivery systems to target cancer with highly potent maytansinoids. Exp Opin Investig Drugs 6: 169-172, 1997.

16. Jordan A, Hadfield JA, Lawrence NJ and McGown AT: Tubulin as a target for anticancer drugs: agents which interact with the mitotic spindle. Med Res Rev 18: 259-296, 1998.

17. Declaration of Helsinki: Recommendations guiding physicians in biomedical research involving human subjects J Am Med Assoc 277: 925-926, 1997.

18. Oken MM, Creech RH, Tormey DC, Horton J, Davis TE, McFadden ET and Carbone PP: Toxicity and response criteria of the Eastern Cooperative Oncology Group. Am J Clin Oncol 5: 649-655, 1982

19. FDA: Guidance for Industry. Bioanalytical Method Validation. www.fda.gov/cder/guidance/4252fnl.pdf, 2001.

20. Gabrielsson J and Weiner D: Pharmacokinetic and Pharmacodynamic Data Analysis: Concepts and Applications. Swedish Pharmaceutical Press, Stockholm, 2000.

21. Wu AM and Senter PD: Arming antibodies: prospects and challenges for immunoconjugates. Nat Biotechnol 23: 1137-1146, 2005.

22. FDA: NDA 21-174/S-002, 2001.
23. Heider KH, Mulder JW, Ostermann E, Susani S, Patzelt E, Pals ST and Adolf GR: Splice variants of the cell surface glycoprotein CD44 associated with metastatic tumour cells are expressed in normal tissues of humans and cynomolgus monkeys. Eur $\mathbf{J}$ Cancer 31A: 2385-2391, 1995.

24. Eagan RT, Ingle JN, Rubin J, Frytak S and Moertel CG: Early clinical study of an intermittent schedule for maytansine (NSC153858): brief communication. J Natl Cancer Inst 60: 93-96, 1978.

25. Eagan RT, Creagan ET, Ingle JN, Frytak S and Rubin J: Phase II evaluation of maytansine in patients with metastatic lung cancer. Cancer Treat Rep 62: 1577-1579, 1978.

26. Chahinian AP, Nogeire C, Ohnuma T, Greenberg ML, Sivak M, Jaffrey IS and Holland JF: Phase I study of weekly maytansine given by iv bolus or 24-h infusion. Cancer Treat Rep 63: 1953-1960, 1979.

27. Blum RH and Kahlert T: Maytansine: a phase I study of an ansa macrolide with antitumor activity. Cancer Treat Rep 62: $435-438,1978$

28. Xie H, Audette C, Hoffee M, Lambert JM and Blattler WA: Pharmacokinetics and biodistribution of the antitumor immunoconjugate, cantuzumab mertansine (huC242-DM1), and its two components in mice. J Pharmacol Exp Ther 308: 1073-1082, 2004.

29. Colnot DR, Quak JJ, Roos JC, van Lingen A, Wilhelm AJ, van Kamp GJ, Huijgens PC, Snow GB and van Dongen GA: Phase I therapy study of $186 \mathrm{Re}$-labeled chimeric monoclonal antibody U36 in patients with squamous cell carcinoma of the head and neck. J Nucl Med 41: 1999-2010, 2000.

30. Koppe M, Schaijk F, Roos J, Leeuwen P, Heider KH, Kuthan H and Bleichrodt R: Safety, pharmacokinetics, immunogenicity, and biodistribution of (186)Re-labeled humanized monoclonal antibody BIWA 4 (Bivatuzumab) in patients with earlystage breast cancer. Cancer Biother Radiopharm 19: 720-729, 2004.

31. Lobo ED, Hansen RJ and Balthasar JP: Antibody pharmacokinetics and pharmacodynamics. J Pharm Sci 93: 2645-2668, 2004.

32. Bauer RJ, Dedrick RL, White ML, Murray MJ and Garovoy MR: Population pharmacokinetics and pharmacodynamics of the anti-CD11a antibody hu1124 in human subjects with psoriasis. J Pharmacokinet Biopharm 27: 397-420, 1999.

33. Kovarik J, Wolf P, Cisterne JM, Mourad G, Lebranchu Y, Lang P, Bourbigot B, Cantarovich D, Girault D, Gerbeau C, Schmidt AG and Soulillou JP: Disposition of basiliximab, an interleukin-2 receptor monoclonal antibody, in recipients of mismatched cadaver renal allografts. Transplantation 64: 1701-1705, 1997.

34. Kuester $\mathrm{K}$ and Kloft C: Pharmacokinetics of monoclonal antibodies. In: Pharmacokinetics and Pharmacodynamics of Biotech Drugs: Principles and Case Studies in Drug Development. Meibohm B (ed). Wiley-VCH, Weinheim, pp45-91, 2006.

35. Chow FS, Benincosa LJ, Sheth SB, Wilson D, Davis CB, Minthorn EA and Jusko WJ: Pharmacokinetic and pharmacodynamic modeling of humanized anti-factor IX antibody (SB 249417) in humans. Clin Pharmacol Ther 71: 235-245, 2002.

36. Dowell JA, Korth-Bradley J, Liu H, King SP and Berger MS: Pharmacokinetics of gemtuzumab ozogamicin, an antibodytargeted chemotherapy agent for the treatment of patients with acute myeloid leukemia in first relapse. J Clin Pharmacol 41: 1206-1214, 2001

37. Everitt DE, Davis CB, Thompson K, Di Cicco R, Ilson B, Demuth SG, Herzyk DJ and Jorkasky DK: The pharmacokinetics, antigenicity, and fusion-inhibition activity of RSHZ19, a humanized monoclonal antibody to respiratory syncytial virus, in healthy volunteers. J Infect Dis 174: 463-469, 1996.

38. Loh A, Sgouros G, O'Donoghue JA, Deland D, Puri D, Capitelli P, Humm JL, Larson SM, Old LJ and Divgi CR: Pharmacokinetic model of iodine-131-G250 antibody in renal cell carcinoma patients. J Nucl Med 39: 484-489, 1998.

39. Tokuda Y, Watanabe T, Omuro Y, Ando M, Katsumata N, Okumura A, Ohta M, Fujii H, Sasaki Y, Niwa T and Tajima T: Dose escalation and pharmacokinetic study of a humanized antiHER2 monoclonal antibody in patients with HER2/neu-overexpressing metastatic breast cancer. Br J Cancer 81: 1419-1425, 1999.

40. Kloft C, Graefe EU, Tanswell P, Scott AM, Hofheinz R, Amelsberg A and Karlsson MO: Population pharmacokinetics of sibrotuzumab, a novel therapeutic monoclonal antibody, in cancer patients. Invest New Drugs 22: 39-52, 2004. 
41. Waldmann TA and Strober W: Metabolism of immunoglobulins. Prog Allergy 13: 1-110, 1969.

42. Morell A, Terry WD and Waldmann TA: Metabolic properties of IgG subclasses in man. J Clin Invest 49: 673-680, 1970.

43. Ghetie V, Popov S, Borvak J, Radu C, Matesoi D, Medesan C, Ober RJ and Ward ES: Increasing the serum persistence of an IgG fragment by random mutagenesis. Nat Biotechnol 15: 637-640, 1997.
44. Kovarik JM, Nashan B, Neuhaus P, Clavien PA, Gerbeau C, Hall ML and Korn A: A population pharmacokinetic screen to identify demographic-clinical covariates of basiliximab in liver transplantation. Clin Pharmacol Ther 69: 201-209, 2001.

45. Wiseman LR and Faulds D: Daclizumab: a review of its use in the prevention of acute rejection in renal transplant recipients. Drugs 58: 1029-1042, 1999. 